Article

\title{
Luminescence and Magnetic Properties of Two Three-Dimensional Terbium and Dysprosium MOFs Based on Azobenzene-4,4'-Dicarboxylic Linker
}

\author{
Belén Fernández ${ }^{1}$, Itziar Oyarzabal ${ }^{2}$, José M. Seco ${ }^{2}$, Eider San Sebastián ${ }^{2}$, \\ David Fairen-Jiménez ${ }^{3}$, Santiago Gómez-Ruiz ${ }^{4}$, Alfonso Salinas-Castillo ${ }^{5}$, \\ Antonio J. Calahorro ${ }^{1}$ and Antonio Rodríguez-Diéguez ${ }^{1 \text {,* }}$ \\ 1 Department of Inorganic Chemistry, University of Granada, 18071 Granada, Spain; \\ belenfernandez@ugr.es (B.F.); ajccasanova@ugr.es (A.J.C.) \\ 2 Department of Applied Chemistry, Faculty of Chemistry, University of the Basque Country UPV/EHU, \\ Paseo Manuel Lardizabal 3, 20018 Donostia-San Sebastián, Spain; itziar_oyarzabal@hotmail.com (I.O.); \\ josemanuel.seco@ehu.es (J.M.S.); eider.sansebastian@ehu.es (E.S.S.) \\ 3 Department of Chemical Engineering \& Biotechnology, University of Cambridge, Pembroke Street, \\ Cambridge CB2 3RA, UK; df334@cam.ac.uk \\ 4 Department of Biology and Geology, Physics and Inorganic Chemistry, E.S.C.E.T., \\ Rey Juan Carlos University, c/ Tulipán s/n, 28933 Móstoles, Spain; santiago.gomez@urjc.es \\ 5 Department of Analytic Chemistry, University of Granada, 18071 Granada, Spain; alfonsos@ugr.es \\ * Correspondence: antonio5@ugr.es; Tel.: +34-958-24-85-24
}

Academic Editor: Guillermo Mínguez Espallargas

Received: 24 October 2015; Accepted: 26 January 2016; Published: 2 February 2016

\begin{abstract}
We report the in situ formation of two novel metal-organic frameworks based on terbium and dysprosium ions using azobenzene- $4,4^{\prime}$-dicarboxylic acid $\left(H_{2} a b d\right)$ as ligand, synthesized by soft hydrothermal routes. Both materials show isostructural three-dimensional networks with channels along $a$ axis and display intense photoluminescence properties in the solid state at room temperature. Textural properties of the metal-organic frameworks (MOFs) have been fully characterized although no appreciable porosity was obtained. Magnetic properties of these materials were studied, highlighting the dysprosium material displays slightly frequency-dependent out of phase signals when measured under zero external field and under an applied field of $1000 \mathrm{Oe.}$
\end{abstract}

Keywords: metal-organic framework; dysprosium; terbium; magnetism; luminescence

\section{Introduction}

Coordination polymers (CPs), also known as metal-organic frameworks (MOFs), have dramatically increased as heterogeneous materials for twenty years. These novel materials have attracted considerable research interest over years as a consequence of their functional properties and potential applications in many scientific areas [1,2]. MOFs are obtained by the self-assembly of metal ions or clusters with appropriate bridging organic ligands. The fact that they can use a variety of metal ions and organic ligands provides the possibility of obtaining a large number of structural motifs generating infinite combinations. The ability to carry out post-synthetic reactions, confer us another synthetic variability to expand the range of targets that we can achieve [3]. The chemistry of Lanthanide-based MOFs has been significantly less explored than that of transition metal-based MOFs, probably due to the fact that lanthanide elements are usually regarded as unsuitable metal centers, as coordination numbers are too high and coordination geometries are hard to control. Over the past few years, however, the design and study of Lanthanide-based MOFs has evolved enormously [4-9] because of their interesting structures and potential applications in areas such as luminescent materials [10], 
selective gas adsorption [11], magnetism [12], sensors, and biological properties [13]. Given that, classically, the first scientific efforts were focused on the use of MOF as possible porous materials for gas storage and separation, the study of their luminescent and magnetic properties have been forgotten. However, increasingly, researchers try to obtain multifunctional MOFs with new interesting physical properties that can give another perspective to MOF's applications, such as luminescence sensors due to metal-ligand charge transfer [14]. In recent years, we have designed and synthesized novel Lanthanide-MOFs with different nitrogen derivative ligands with interesting luminescent properties [15] and constructed single-molecule magnets (SMM) based on dysprosium, able to show interesting effective energy barriers $[16,17]$. Lately, we have managed to synthesize Ln-MOFs with SMM behavior, demonstrating the potential of these dicarboxylic linkers to construct new MOFs with novel and interesting properties in this field [18].

Looking among other ligands, the versatile azobenzene- $4,4^{\prime}$-dicarboxylate $(a b d)^{2-}$ linker (Scheme 1) has been used in the preparation of various carboxylate complexes, owing to its rich variety of coordination modes [19]. Moreover, $\mathrm{H}_{2} a b d$ is a good candidate to show enhanced emissive properties, which are, in principle, tunable by coordination to metal with different chemical environments. Here, we report the synthesis, structure, luminescence, adsorption and magnetic properties of two isostructural 3D-MOFs $\left\{\left[\mathrm{Tb}(\mathrm{abd})_{1.5}\left(\mathrm{H}_{2} \mathrm{O}\right)_{2}(\mathrm{DMF})\right] \cdot\left(\mathrm{H}_{2} \mathrm{O}\right)_{2} \cdot(\mathrm{DMF})_{2}\right\}_{\mathrm{n}}(\mathbf{1})$ and $\left\{\left[\mathrm{Dy}(\mathrm{abd})_{1.5}\left(\mathrm{H}_{2} \mathrm{O}\right)_{2}(\mathrm{DMF})\right] \cdot\left(\mathrm{H}_{2} \mathrm{O}\right)_{2} \cdot(\mathrm{DMF})_{2}\right\}_{n}$ (2). As we expected, these MOFs are multifunctional materials, particularly the dysprosium material, which shows frequency-dependent out of phase signals when measured under zero external field and under an applied field of 1000 Oe.

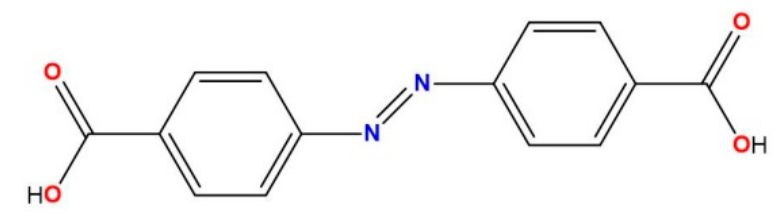

Scheme 1. Azobenzene- $4,4^{\prime}$-dicarboxylic acid $\left(H_{2} a b d\right)$.

\section{Experimental Section}

\subsection{General Procedures}

Unless stated otherwise, all reactions were conducted using hydrothermal conditions. Lanthanide salts and azobenzene-4, $4^{\prime}$-dicarboxylic acid were purchased commercially (Sigma-Aldrich, Madrid, Spain) and used without further purification.

\subsection{Preparation of Complexes}

$\left\{\left[\mathrm{Tb}(\mathrm{abd})_{1.5}\left(\mathrm{H}_{2} \mathrm{O}\right)_{2}(\mathrm{DMF})\right] \cdot\left(\mathrm{H}_{2} \mathrm{O}\right)_{2} \cdot(\mathrm{DMF})_{2}\right\}_{n}(\mathbf{1})$ : Solvothermal routes were used for the synthesis of this compound. An amount of $0.810 \mathrm{~g}(3 \mathrm{mmol})$ of $\mathrm{H}_{2} a b d$ were added to $5 \mathrm{~mL}$ of DMF and the resulting mixture was sonicated for $10 \mathrm{~min}$. To this solution, $1.21 \mathrm{~g}(2 \mathrm{mmol})$ of $\mathrm{Tb}\left(\mathrm{CF}_{3} \mathrm{SO}_{3}\right)_{3}$ in $5 \mathrm{~mL}$ of DMF were added and the resulting solution was sealed in a Teflon autoclave and placed into a preheated oven at $95{ }^{\circ} \mathrm{C}$ for $48 \mathrm{~h}$. The oven was then opened, and the sealed autoclave was allowed to cool naturally to ambient temperature. The autoclave was opened, the mixture filtered, and the filtrate was allowed to stand at room temperature for several days whereupon orange prismatic crystals of $\mathbf{1}$ were formed. The crystals were collected by filtration, washed with DMF and dried in a vacuum. Yield: $c a$. $35 \%$; Elemental analysis (\%) of $\mathrm{C}_{30} \mathrm{H}_{41} \mathrm{~N}_{6} \mathrm{O}_{13} \mathrm{~Tb}$, calcd: C 42.26, H 4.85, N 9.86; found: C 42.64, H 4.62, N 10.18.

$\left\{\left[\mathrm{Dy}(\mathrm{abd})_{1.5}\left(\mathrm{H}_{2} \mathrm{O}\right)_{2}(\mathrm{DMF})\right] \cdot\left(\mathrm{H}_{2} \mathrm{O}\right)_{2} \cdot(\mathrm{DMF})_{2}\right\}_{n}(2)$ : We carried out the same reaction as in the above compound but using $\mathrm{Dy}\left(\mathrm{CF}_{3} \mathrm{SO}_{3}\right)_{3}(2 \mathrm{mmol})$. Orange powder of the compound under study were obtained. Yield: $45 \%$, based on Dy. Anal. Calcd. $\mathrm{C}_{30} \mathrm{H}_{41} \mathrm{~N}_{6} \mathrm{O}_{13}$ Dy: $\mathrm{C} 42.08, \mathrm{H}$ 4.83, N 9.82. Found: C 42.17, H 4.79, N 10.03 . 


\subsection{Physical Measurements}

Elemental analyses were carried out at the Centro de Instrumentación Científica (University of Granada) on a Fisons-Carlo Erba analyzer model EA 1108 (Thermo Scientific, Waltham, MA, USA).

\subsection{Single-Crystal Structure Determination}

The crystal structure of $\mathbf{1}$ was determined by single crystal X-ray crystallography. Suitable crystal of this material was mounted on a glass fibre and used for data collection on a Bruker AXS APEX CCD area detector (Bruker, Billerica, MA, USA) equipped with graphite monochromated MoK $\alpha$ radiation $(\lambda=0.71073 \AA)$. Lorentz-polarization and empirical absorption corrections were applied [20]. The structures were solved using direct methods and refined with full-matrix least-squares calculations on $F^{2}$ using the program SHELX-97 [21]. Anisotropic temperature factors were assigned to all atoms except for hydrogen atoms, which are riding their parent atoms with an isotropic temperature factor, arbitrarily chosen as 1.2 times that of the respective parent. Attempts to solve disorder problems with two crystallization water molecules failed in compound 1. Instead, a new set of $F^{2}$ (hkl) values with the contribution from solvent molecule withdrawn was obtained using the SQUEEZE procedure implemented in PLATON-94 [22]. Final $\mathrm{R}(\mathrm{F}), w R\left(F^{2}\right)$ and goodness of fit agreement factors, details on the data collection and analysis can be found in Table 1. Compounds $\mathbf{1}$ and $\mathbf{2}$ are isostructural materials. We carried out a LeBail refinement (Figure S1) with TOPAS [23] software to establish the purity and the unit cell of the powders pertaining to 2. Cambridge Crystallographic Data Centre (CCDC) reference number for 1 is 1049582. Copies of the data can be obtained free of charge upon application to CCDC, 12 Union Road, Cambridge CB2 1EZ, U.K. (Fax: +44-1223-336-033; www.ccdc.cam.ac.uk/deposit).

Table 1. Crystallographic data and structural refinement details for $\mathbf{1}$.

\begin{tabular}{cc}
\hline Compound & $\mathbf{1}$ \\
\hline Chemical formula & $\mathrm{C}_{30} \mathrm{H}_{41} \mathrm{~N}_{6} \mathrm{O}_{13} \mathrm{~Tb}$ \\
$\mathrm{M} /$ gmol $^{-1}$ & 852.61 \\
$\mathrm{~T}(\mathrm{~K})$ & $100(2)$ \\
$\lambda / \AA$ & 0.71073 \\
Crystal system & Triclinic \\
Space group & $P-1$ \\
$\mathrm{a} / \AA$ & $9.7799(5)$ \\
$\mathrm{b} / \AA$ & $11.5661(7)$ \\
$\mathrm{c} / \AA$ & $16.7597(10)$ \\
$\alpha / \mathrm{deg}$ & $105.886(2)$ \\
$\beta / \mathrm{deg}$ & $100.772(2)$ \\
$\gamma / \mathrm{deg}$ & $100.290(2)$ \\
$V / \AA^{3}$ & $1,737.46(17)$ \\
$\mathrm{Z}$ & 2 \\
$\rho_{\text {calcd }}\left(\mathrm{g} \cdot \mathrm{cm}^{-3}\right)$ & 1.630 \\
$\mu\left(\mathrm{mm}^{-1}\right)$ & 2.108 \\
$R($ int $)$ & 0.0741 \\
$\mathrm{GOF}$ on $\mathrm{F} 2$ & 1.026 \\
$R_{1}[I>2 \sigma(I)]$ & 0.0544 \\
$w R^{2}[I>2 \sigma(I)]$ & 0.1173 \\
\hline$R_{1}=\Sigma|| \mathrm{F}_{0}|-| \mathrm{F}_{\mathrm{c}}|| / \Sigma\left|\mathrm{F}_{0}\right| ; w R^{2}=\left[\Sigma w\left(\mathrm{~F}_{0}{ }^{2}-\mathrm{F}_{\mathrm{c}}{ }^{2}\right)^{2} / \Sigma w \mathrm{~F}_{0}{ }^{2}\right]^{1 / 2}$. \\
\end{tabular}

\subsection{Luminescence Measurements}

A Varian Cary-Eclipse Fluorescence Spectrofluorimeter (Agilent Technologies, Madrid, Spain) was used to obtain the fluorescence spectra. The spectrofluorimeter was equipped with a xenon discharge lamp (peak power equivalent to $75 \mathrm{~kW}$ ), Czerny-Turner monochromators, R-928 photomultiplier tube, which is red sensitive (even $900 \mathrm{~nm}$ ), with manual or automatic voltage controlled using the Cary 
Eclipse software for Windows 95/98/NT system. The photomultiplier detector voltage was $700 \mathrm{~V}$ and the instrument excitation and emission slits were set at 5 and $5 \mathrm{~nm}$, respectively.

\subsection{Computational Calculations}

The material was characterized geometrically, starting from the crystallographic coordinates. The pore size distribution (Figure S2) was calculated using the method of Gelb and Gubbins, where the largest sphere that can fit in a random point within a structure without overlapping the van der Waals surface of the framework recorded for a large number of random points [24,25].

\subsection{Magnetic Measurements}

Magnetization and variable-temperature (1.9-300 K) magnetic susceptibility measurements on polycrystalline samples were carried out with a Quantum Design SQUID MPMS XL-5 device (Quantum Design, San Diego, CA, USA) operating at different magnetic fields. The experimental susceptibilities were corrected for the diamagnetism of the constituent atoms by using Pascal's tables. Ac susceptibility measurements under different applied static fields were performed by using an oscillating ac field of 3.5 Oe on a PPMS 6000 magnetometer.

\section{Results and Discussion}

The hydrothermal reaction of the appropriate lanthanide trifluoromethanesulfonate $(2 \mathrm{mmol})$ with the azobenzene-4, $4^{\prime}$-dicarboxylic acid $(3 \mathrm{mmol})$ in dimethylformamide $(10 \mathrm{~mL})$ at $95{ }^{\circ} \mathrm{C}$ for $48 \mathrm{~h}$ produced prismatic orange crystals of these 3D-MOFs. The crystal structure of the terbium compound was determined using single crystal X-ray crystallography.

\subsection{Description of the Structure}

Compound 1 crystallizes in the triclinic space group P-1. The 3D-MOF structure is composed of $\mathrm{Tb}$ (III) chains (Figure 1) connected by oxygen atoms pertaining to the carboxylate groups of the $(a b d)^{2-}$ ligands. In material $\mathbf{1}$, the $(a b d)^{2-}$ linker shows a bis-bridging intradinuclear coordination mode.

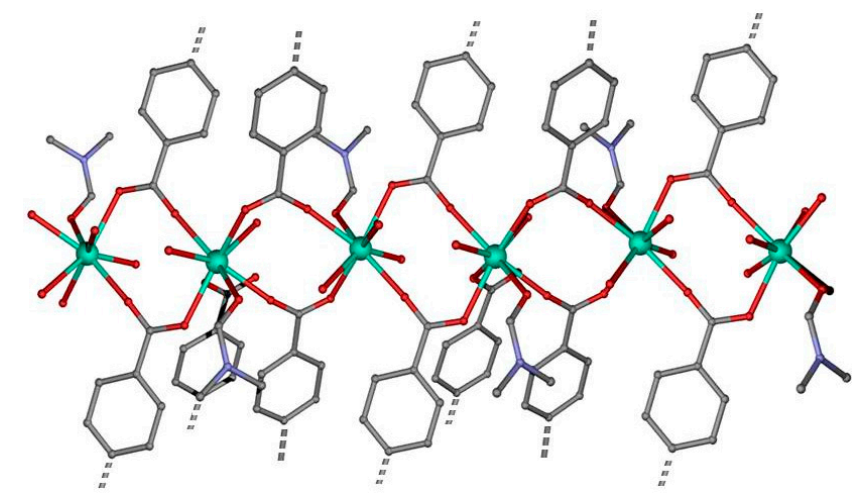

Figure 1. Perspective view of one of the chains that forms the 3D-MOF by double carboxylate-bridge through $(a b d)^{2-}$ linker.

The $\mathrm{TbO}_{8}$ coordination polyhedron is formed by five oxygen atoms of carboxylate groups pertaining to five different $(a b d)^{2-}$ ligands, two water molecules and one oxygen atom from one DMF coordinated molecule. The Tb-O bond distances are in the range 2.307(4)-2.497 $\AA$, in which the largest corresponds to $\mathrm{Tb}-\mathrm{O}_{\mathrm{DMF}}$ distance. In the terbium chain, the terbium ions are bridged by a double carboxylate-bridge through $(a b d)^{2-}$ linker in which the $\mathrm{Tb} \cdots \mathrm{Tb}$ distance has a value of $4.779 \AA$, while the shortest interchain $\mathrm{Tb} \cdots \mathrm{Tb}$ distance is of $16.760 \AA$. As above, this MOF can be described by terbium chains bridged by $(a b d)^{2-}$ linkers generating a three-dimensional network (Figure 2 ) with 
channels along $a$ axis with DMF solvent molecules inside. These crystallization DMF molecules are involved in strong hydrogen bonds $(2.686 \AA)$ with the coordinated water molecule O2W.

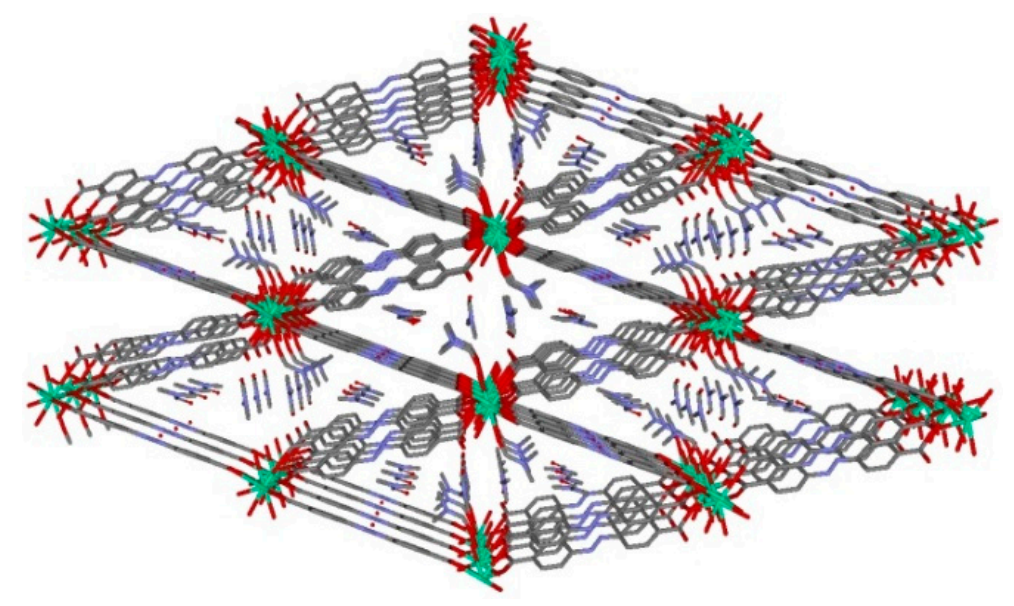

Figure 2. View down a axis of channels in MOF 1. Hydrogen atoms have been omitted for clarity. Color code $\mathrm{N}$ = blue, $\mathrm{O}=$ red, $\mathrm{C}=$ grey, $\mathrm{Tb}$ = green.

The hydrothermal reaction of dysprosium trifluoromethanesulfonate with azobenzene-4,4'-dicarboxylic acid in dimethylformamide produced prismatic orange crystals. The crystal structure of dysprosium material 2 was determined using powder $\mathrm{X}$-ray diffraction. The structure is isostructural to $\mathbf{1}$, corroborated by LeBail refinement (Figure S1) implemented in Topas-R.

\subsection{Adsorption Properties}

$\mathrm{N}_{2}$ adsorption isotherms in MOF 1 were undertaken at $77 \mathrm{~K}$ using a Micromeritics 3Flex instrument. Samples were activated at $393 \mathrm{~K}$ for $8 \mathrm{~h}$ previous to the adsorption measurement; however, no appreciable porosity was obtained. Following this, we studied the existence of potential changes in the structure during the activation by running a PXRD after the treatment. However, no differences were found before and after the experiment, confirming the no existence of important changes in the structure of the bulk solid. In this context, we and others have found before that the presence of densified layers at the surface of the material may prevent the entry of small molecular species into the bulk porosity $[26,27]$.

\subsection{Luminescence Studies}

Figure 3 shows the emission spectra of $\mathbf{1}$ and $\mathbf{2}$ in the solid state at room temperature. Broad intense emission bands are observed for 1 , centred at $c a . \lambda=453$ and $488 \mathrm{~nm}$ upon excitation at $\lambda=330 \mathrm{~nm}$. The emission of $\mathbf{2}$, however, is significantly blue-shifted compared to that of $\mathbf{1}$, with similar emission bands centered at $\lambda=475$ and $508 \mathrm{~nm}$. The latter shift should be derived from a charge-transfer phenomenon attributed to the breach of a conjugated system of $\sigma$ and $\pi$ bonds in the carboxylate groups arisen from the coordination of the ligand and Ln centers, as reported in recent literature in the field [28-30].

The luminescence excitation spectrum of 1 was investigated under the typical emission ( $540 \mathrm{~nm}$ ) of the terbium(III) ion at room temperature. Figure 4 shows the emission spectrum of this compound at $\lambda_{e x}=380 \mathrm{~nm}$. Four characteristic peaks of $\mathrm{Tb}^{3+}$ are assigned to the ${ }^{5} \mathrm{D}_{4} \rightarrow{ }^{7} \mathrm{~F}_{\mathrm{J}}$ transitions, namely, ${ }^{5} \mathrm{D}_{4} \rightarrow{ }^{7} \mathrm{~F}_{6}(485 \mathrm{~nm}),{ }^{5} \mathrm{D}_{4} \rightarrow{ }^{7} \mathrm{~F}_{5}(538 \mathrm{~nm}),{ }^{5} \mathrm{D}_{4} \rightarrow{ }^{7} \mathrm{~F}_{4}(579 \mathrm{~nm})$, and ${ }^{5} \mathrm{D}_{4} \rightarrow{ }^{7} \mathrm{~F}_{3}(608 \mathrm{~nm})$, respectively. The most intense emission peak is the hypersensitive transition ${ }^{5} \mathrm{D}_{4} \rightarrow{ }^{7} \mathrm{~F}_{5}[31,32]$. This strong intensity of $\mathbf{1}$ makes it a desired candidate for luminescence-emitting materials. 


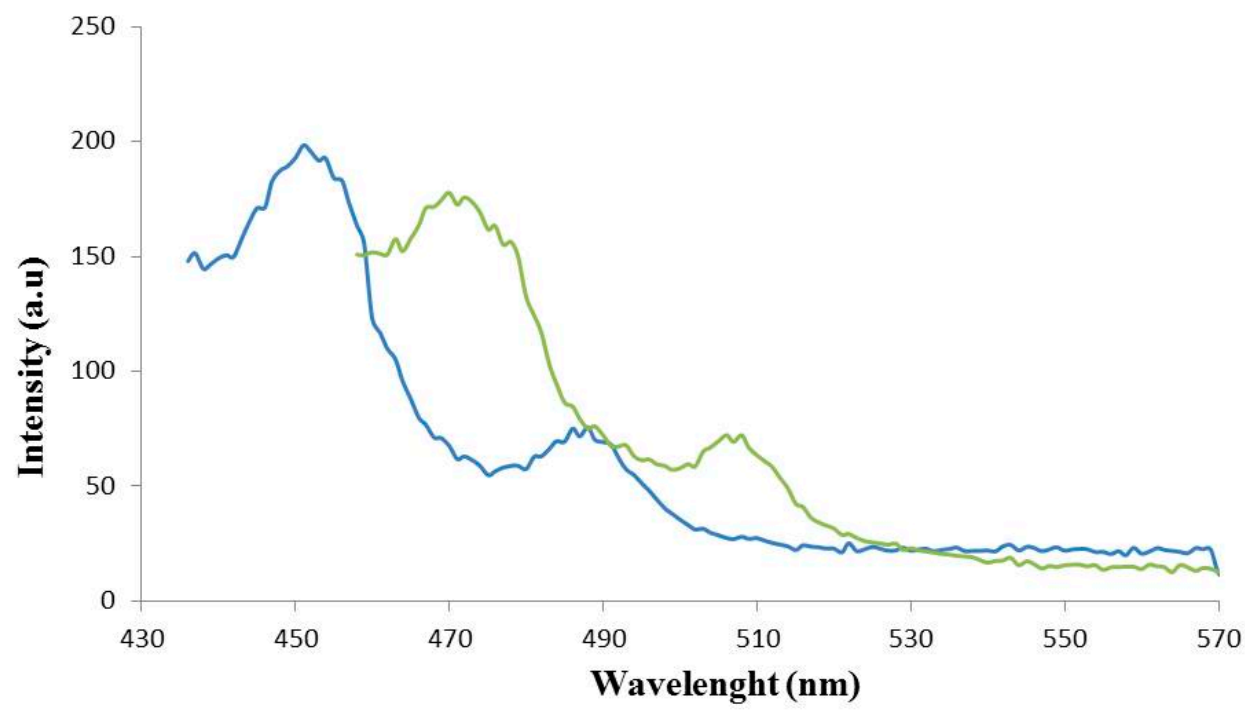

Figure 3. Experimental emission spectra of $\mathbf{1}$ (blue line) and $\mathbf{2}$ (green line). Horizontal axis: wavelength $(\mathrm{nm})$; vertical axis: intensity (arbitrary units, a.u.).

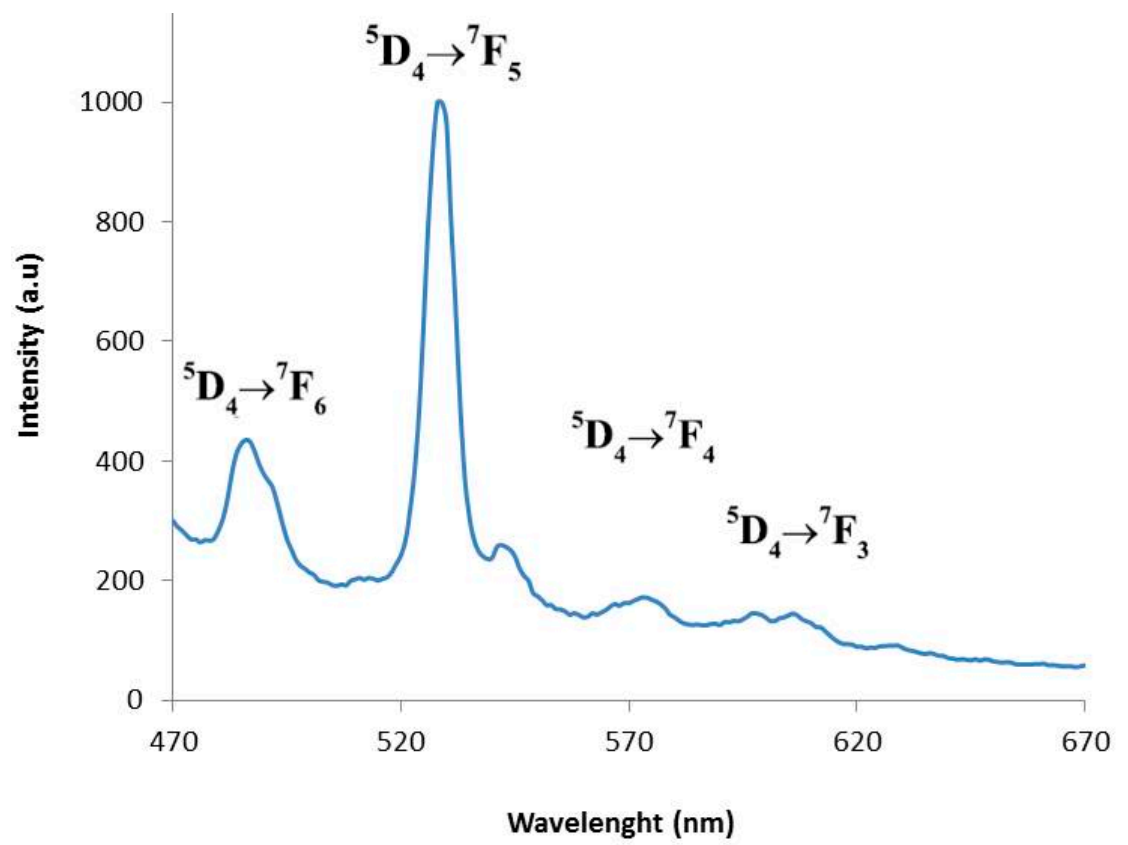

Figure 4. Emission spectrum of terbium MOF.

\subsection{Magnetic Properties}

Figure 5 shows the temperature dependences of the magnetic susceptibilities for compounds 1 and 2 measured on polycrystalline samples in the 2-300 K temperature range under an applied field of $0.1 \mathrm{~T}$. The observed $\chi_{M} T$ values at room temperature of 11.46 and $13.90 \mathrm{~cm}^{3} \cdot \mathrm{K} \cdot \mathrm{mol}^{-1}$, respectively, for 1 and 2 are close to those expected for independent $\mathrm{Ln}^{\mathrm{III}}$ ions in the free-ion approximation $\left(11.82 \mathrm{~cm}^{3} \cdot \mathrm{K} \cdot \mathrm{mol}^{-1}\right.$ for 1 and $14.17 \mathrm{~cm}^{3} \cdot \mathrm{K} \cdot \mathrm{mol}^{-1}$ for 2$)$. 


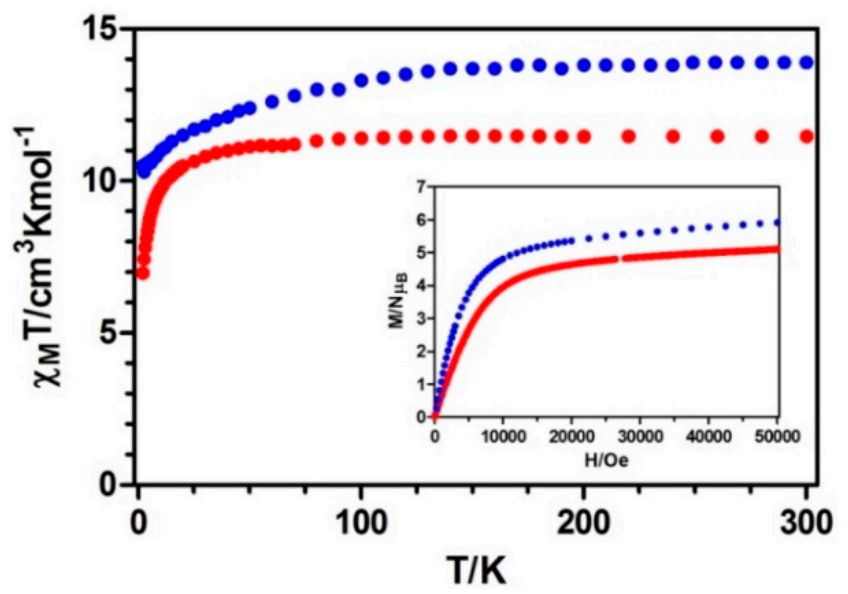

Figure 5. Temperature dependence of the $\chi_{M} T$ product at 1000 Oe for $\mathbf{1}$ and 2. Inset: $M$ versus $H$ plots for complexes 1 and 2. Terbium (red) and Dysprosium (blue).

On lowering the temperature, $\chi_{M} T$ values experience a progressive decrease, as expected for the selective depopulation of the excited Stark sublevels. However, this magnetic response could also involve a significant contribution from antiferromagnetic exchange interactions between lanthanide ions, as anti-syn carboxylate bridges are known to mediate both ferro and antiferromagnetic interactions. The linear fit of $\chi_{M}{ }^{-1}$ vs. $T$ in the high temperature range obeys the Curie-Weiss law $1 / \chi_{M} T=(T-\theta) / C$, with values of $C=11.47, \theta=-0.161$ and $C=14.19, \theta=-5.831$, respectively for 1 and 2 (Figure S3). Due to the presence of strong spin-orbit coupling effects in $\mathrm{Tb}^{3+}$ and $\mathrm{Dy}^{3+}$ ions, it is difficult to conclude if the small and negative Weiss temperatures indicate antiferromagnetic interactions between adjacent $\mathrm{Ln}^{3+}$ ions. The lack of an appropriate model to determine the two contributions in such 3D systems with large anisotropy prevents us from knowing the nature of the magnetic interactions.

The field dependence of the molar magnetization at $2 \mathrm{~K}$ for $\mathbf{1}$ and $\mathbf{2}$ shows a relatively rapid increase at low fields, followed by a very slow increase at high fields without reaching a complete saturation at $5 \mathrm{~T}$. This behavior indicates the presence of magnetic anisotropy and/or the lack of a well-defined ground state, suggesting the presence of low-lying excited states. These low-lying excited states are in agreement with the weak magnetic interactions expected for $4 \mathrm{f}-4 \mathrm{f}$ systems. To further investigate the dynamics of magnetization, we also performed alternating current $(\mathrm{AC})$ magnetic measurements on $\mathbf{1}$ and $\mathbf{2}$. Whereas no out-of-phase $\left(\chi^{\prime \prime}{ }_{M}\right)$ signal was observed for compound $\mathbf{1}$, compound 2 displayed slightly frequency-dependent out of phase signals when measured under zero direct current (DC) external field, but without any maxima in the temperature window technically available, which could be due to the quantum tunneling of the magnetization (Figure 6, top).

When the measurements were performed under an applied field of $1000 \mathrm{Oe}$, no significant improvement was observed, showing only a slight frequency-dependency of the out-of-phase magnetic susceptibility (Figure 6, bottom). 

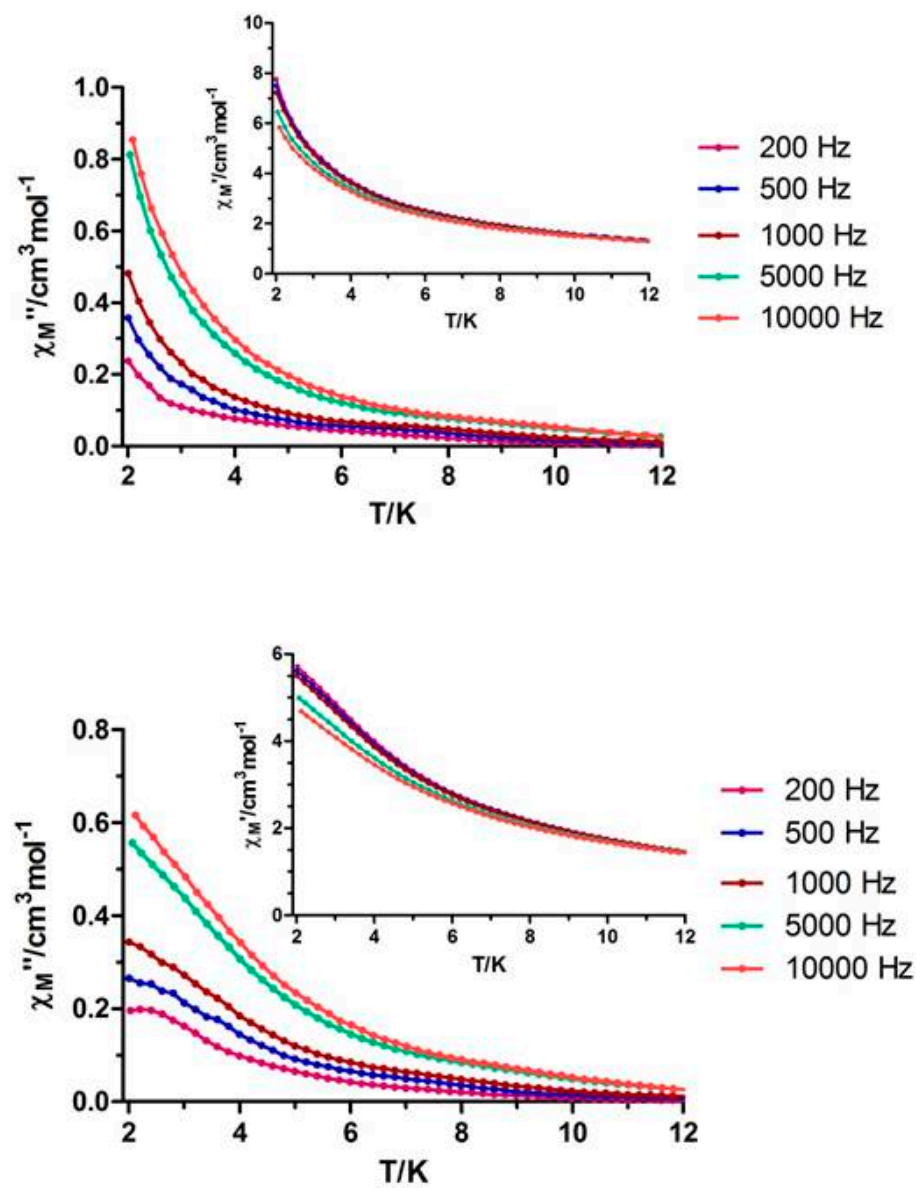

Figure 6. (Top) Temperature dependence of in-phase $\chi_{M}^{\prime}$ (inset) and out-of phase $\chi^{\prime \prime}{ }_{M}$ components of the alternating current (AC) susceptibility for complex 2 under zero applied external field; (Bottom) Temperature dependence of in-phase $\chi^{\prime}{ }_{M}$ (inset) and out-of phase $\chi^{\prime \prime}{ }_{M}$ components of the alternating current (AC) susceptibility for complex 2 under an applied field of 1000 Oe.

\section{Conclusions}

We have succeeded in the design, synthesis, and characterization of the physical properties of two new MOFs, based on terbium and dysprosium with the interesting azobenzene- $4,4^{\prime}$-dicarboxylic acid ligand. These MOFs show isostructural three-dimensional networks and display intense photoluminescence properties in the solid state at room temperature that have been fully characterized. The dysprosium material displays slightly frequency-dependent out-of-phase signals. Therefore, the linkage of luminescence signal and potential magnetic properties of the compounds could signify their utility as multifunctional materials.

Supplementary Materials: The following are available online at www.mdpi.com/2073-4360/8/2/39/s1. Table S1: Selected bond distances $(\AA)$ and Angles $\left(^{\circ}\right) 1$; Figure S1: Lebail Refinement for 2: $a=9.93, b=11.67, c=16.70$, $\alpha=106.37, \beta=100.98, \gamma=100.53, V=1765.77$, sample displacement $=-0.151 \mathrm{~mm}$; Figure S2: Pore size distribution; Figure S3: Curie-Weiss fit of the $\chi_{M}{ }^{-1}$ vs. T curves of compounds 1 (top) and 2 (bottom); Figure S4: TGA spectra of MOFs 1 (green) and 2 (blue); Figure S5: UV spectra of compounds 1 (dark blue) and 2 (sky-blue).

Acknowledgments: This work was supported by the MEC of Spain (Project CTQ2011-24478) and the Junta de Andalucía (FQM-1484 and FQM-195). David Fairen-Jiménez thanks the Royal Society for a University Research Fellowship. Itziar Oyarzabal is grateful to the Departamento de Educación, Universidades e Investigación del Gobierno Vasco for a predoctoral fellowship. The authors thank for technical and human support provided by SG Iker Gipuzkoa of UPV / EHU. 
Author Contributions: Belén Fernández performed the luminescence experiments and assisted in the manuscript preparation. Itziar Oyarzabal and José M. Seco, performed the magnetisms studies and provided useful insights for data interpretations. Eider San Sebastián conceived and designed the theoretical luminescence experiments and analyzed the data. David Fairen-Jiménez and Santiago Gómez-Ruiz, conducted the adsorption experiments. Antonio J. Calahorro synthesized the Dy material under study. Alfonso Salinas-Castillo performed the UV spectra suggested by referee in the last revision. Antonio Rodríguez-Diéguez designed the experiments, analyzed the data, as well as, prepared the manuscriptand was the leader of the study. All authors listed have contributed significantly to this work.

Conflicts of Interest: The authors declare no conflict of interest.

\section{References}

1. Farha, O.K.; Yazaydın, A.O.; Eryazici, I.; Malliakas, C.D.; Hauser, B.D.; Kanatzidis, M.G.; Nguyen, S.T.; Snurr, R.Q.; Hupp, J.T. De novo synthesis of a metal-organic framework material featuring ultrahigh surface area and gas storage capacities. Nat. Chem. 2010, 2, 944-948. [CrossRef] [PubMed]

2. Tian, T.; Velazquez-Garcia, J.; Bennett, T.D.; Fairen-Jimenez, D. Mechanically and chemically robust ZIF-8 monoliths with high volumetric adsorption capacity. J. Mater. Chem. A 2015, 3, 2999-3005. [CrossRef]

3. Kreno, L.E.; Leong, K.; Farha, O.K.; Allendorf, M.; van Duyne, R.P.; Hupp, J.T. Metal-organic framework materials as chemical sensors. Chem. Rev. 2012, 112, 1105-1125. [CrossRef] [PubMed]

4. Almeida Paz, F.A.; Klinowski, J. Hydrothermal synthesis of a novel thermally stable three-dimensional ytterbium-organic framework. Chem. Commun. 2003, 13, 1484-1485. [CrossRef]

5. Sun, D.; Cao, R.; Liang, Y.; Shi, Q.; Hong, M.J. Syntheses, crystal structures and properties of two novel lanthanide-carboxylate polymeric complexes. J. Chem. Soc. Dalton Trans. 2002, 8, 1847-1851. [CrossRef]

6. Long, D.-L.; Blake, A.J.; Champness, N.R.; Wilson, C.; Schroeder, M. Unprecedented seven- and eight-connected lanthanide coordination networks. Angew. Chem. Int. Ed. 2001, 40, 2443-2447. [CrossRef]

7. Westin, L.G.; Kritikos, M.; Caneschi, A. Self assembly, structure and properties of the decanuclear lanthanide ring complex, $\mathrm{Dy}_{10}\left(\mathrm{OC}_{2} \mathrm{H}_{40} \mathrm{CH}_{3}\right)_{30}$. Chem. Commun. 2003, 8, 1012-1013. [CrossRef]

8. Wu, C.-D.; Lu, C.-Z.; Zhuang, H.-H.; Hang, J.-S. Hydrothermal assembly of a novel three-dimensional framework formed by $\left[\mathrm{GdMo}_{12} \mathrm{O}_{42}\right]^{9-}$ anions and nine coordinated $\mathrm{Gd}^{\mathrm{III}}$ cations. J. Am. Chem. Soc. 2002, 124, 3836-3837. [CrossRef]

9. Ma, B.-Q.; Zhang, D.-S.; Gao, S.; Jin, T.-Z.; Yan, C.-H.; Xu, G.-X. From cubane to supercubane: The design, synthesis, and structure of a three-dimensional open framework based on a $\mathrm{Ln}_{4} \mathrm{O}_{4}$ cluster. Angew. Chem. Int. Ed. 2000, 39, 3644-3646. [CrossRef]

10. Li, H.-Y.; Wei, Y.-L.; Dong, X.-Y.; Zang, S.-Q.; Mak, T.C.W. Novel Tb-MOF embedded with viologen species for multi-photofunctionality: Photochromism, photomodulated fluorescence, and luminescent $\mathrm{pH}$ sensing. Chem. Mater. 2015, 27, 1327-1331. [CrossRef]

11. Biswas, S.; Jena, H.S.; Goswami, S.; Sanda, S.; Konar, S. Synthesis and characterization of two lanthanide $\left(\mathrm{Gd}^{3+}\right.$ and $\left.\mathrm{Dy}^{3+}\right)$-based three-dimensional metal organic frameworks with squashed metallomacrocycle type building blocks and their magnetic, sorption, and fluorescence properties study. Cryst. Growth Des. 2014, 14, 1287-1295. [CrossRef]

12. Baldov, J.J.; Coronado, E.; Gaita-Ariño, A.; Gamer, C.; Giménez-Marqués, M.; Mínguez-Espallargas, G. A SIM-MOF: Three-dimensional organisation of single-ion magnets with anion-exchange capabilities. Chem. Eur. J. 2014, 20, 10695-10702. [CrossRef] [PubMed]

13. Briones, D.; Fernandez, B.; Calahorro, A.J.; Fairen-Jimenez, D.; Sanz, R.; Martínez, F.; Orcajo, G.; San Sebastian, E.; Seco, J.M.; Sánchez González, C.; et al. Highly active anti-diabetic metal-organic framework. Cryst. Growth Des. 2016. [CrossRef]

14. Cuia, Y.; Chena, B.; Qian, G. Lanthanide metal-organic frameworks for luminescent sensing and light-emitting applications. Coord. Chem. Rev. 2014, 273, 76-86. [CrossRef]

15. Rodríguez-Diéguez, A.; Salinas-Castillo, A.; Sironi, A.; Seco, J.M.; Colacio, E. A chiral diamondoid 3D lanthanum metal-organic framework displaying blue-greenish long lifetime photoluminescence emission. Cryst. Eng. Comm. 2010, 12, 1876-1879. [CrossRef]

16. Ruiz, J.; Mota, A.J.; Rodríguez-Diéguez, A.; Titos, S.; Herrera, J.M.; Ruiz, E.; Cremades, E.; Pierre Costes, J.; Colacio, E. Field and dilution effects on the slow relaxation of a luminescent DyO9 low-symmetry single-ion magnet. Chem. Commun. 2012, 48, 7916-7918. [CrossRef] [PubMed] 
17. Oyarzabal, I.; Ruiz, J.; Seco, J.M.; Evangelisti, M.; Camón, A.; Ruiz, E.; Aravena, D.; Colacio, E. Rational electrostatic design of easy-axis magnetic anisotropy in a $\mathrm{Zn}^{\mathrm{II}}-\mathrm{Dy}{ }^{\mathrm{III}}-\mathrm{Zn}^{\mathrm{II}}$ single-molecule magnet with a high energy barrier. Chem. Eur. J. 2014, 20, 14262-14269. [CrossRef] [PubMed]

18. Calahorro, A.J.; Oyarzabal, I.; Fernández, B.; Seco, J.M.; Tian, T.; Fairen-Jimenez, D.; Colacio, E.; Rodríguez-Diéguez, A. Rare earth anthracenedicarboxylate metal-organic frameworks: Slow relaxation of magnetization of $\mathrm{Nd}^{3+}, \mathrm{Gd}^{3+}, \mathrm{Dy}^{3+}, \mathrm{Er}^{3+}$ and $\mathrm{Yb}^{3+}$ based materials. Dalton Trans. 2016, 45, 591-598. [CrossRef]

19. Zhuang, J.-L.; Lommel, K.; Ceglarek, D.; Andrusenko, I.; Kolb, U.; Maracke, S.; Sazama, U.; Froba, M.; Terfort, A. Synthesis of a new copper-azobenzene dicarboxylate framework in the form of hierarchical bulk solids and thin films without and with patterning. Chem. Mater. 2011, 23, 5366-5474. [CrossRef]

20. Sheldrick, G.M. SADABS, Program for Empirical Adsorption Correction; Institute for Inorganic Chemistry, University of Gottingen: Gottingen, Germany, 1996.

21. Sheldrick, G.M. SHELX97, Program for Crystal Structure Refinement; University of Göttingen: Göttingen, Germany, 1997.

22. Spek, A.L. PLATON-94 (V-101094), a Multipurpose Crystallographic Tool; University of Utrecht: Utrecht, The Netherlands, 1994.

23. Topas-R Software; General profile and structure analysis software for powder diffraction data; Bruker AXS: Brisbane, Australia, 2012.

24. Gelb, L.D.; Gubbins, K.E. Pore size distributions in porous glasses: a computer simulation study. Langmuir 1999, 15, 305-308. [CrossRef]

25. Düren, T.; Millange, F.; Férey, G.; Walton, K.S.; Snurr, R.Q. Calculating geometric surface areas as a characterization tool for metal-organic frameworks. J. Phys. Chem. C 2007, 111, 15350-15356. [CrossRef]

26. Seco, J.M.; Fairen-Jimenez, D.; Calahorro, A.J.; Mendez-Linan, L.; Perez-Mendoza, M.; Casati, N.; Colacio, E.; Rodriguez-Dieguez, A. Modular structure of a robust microporous MOF based on $\mathrm{Cu}_{2}$ paddle-wheels with high $\mathrm{CO}_{2}$ selectivity. Chem. Commun. 2013, 49, 11329-11331. [CrossRef] [PubMed]

27. Feldblyum, J.I.; Liu, M.; Gidley, D.W.; Matzger, A.J. Reconciling the discrepancies between crystallographic porosity and guest access as exemplified by Zn-HKUST-1. J. Am. Chem. Soc. 2011, 133, 18257-18263. [CrossRef] [PubMed]

28. Tan, A.-D.; Zhao, B.; Liu, L.; Dai, J.-C. Synthesis, structure, and characterization of polymeric lanthanide 2-aminoterephthalate frameworks $\left[\operatorname{Ln}_{2}(\operatorname{atp})_{3}\left(\mathrm{H}_{2} \mathrm{O}\right)_{2}\right] \cdot \mathrm{dmf} \cdot 4 \mathrm{H}_{2} \mathrm{O}$. Inorg. Chem. Comm. 2015, 61, 140-143. [CrossRef]

29. Almáši, M.; Zeleňák, V.; Galdun, L.; Kuchár, J. First 3D coordination polymer built from Ho(III) and 2-aminoterephthalate ligand. Inorg. Chem. Commun. 2014, 39, 39-42. [CrossRef]

30. Calahorro, A.J.; Peñas-Sanjuan, A.; Melguizo, M.; Fairén-Jiménez, D.; Zaragoza, G.; Fernández, B.; Salinas-Castillo, A.; Rodríguez-Diéguez, A. First examples of metal-organic frameworks with the novel 3,3'-(1,2,4,5-tetrazine-3,6-diyl)dibenzoic spacer. Luminescence and adsorption properties. Inorg. Chem. 2013, 52, 546-548. [CrossRef] [PubMed]

31. Shyni, R.; Biju, S.; Reddy, M.L.P.; Cowley, A.H.; Findlater, M. Synthesis, crystal structures, and photophysical properties of homodinuclear lanthanide xanthene-9-carboxylates. Inorg. Chem. 2007, 46, 11025-11030. [CrossRef] [PubMed]

32. Wang, Y.W.; Zhang, Y.L.; Dou, W.; Zhang, A.J.; Qin, W.W.; Liu, W.S. Synthesis, radii dependent self-assembly crystal structures and luminescent properties of rare earth (III) complexes with a tripodal salicylic derivative. Dalton Trans. 2010, 39, 9013-9021. [CrossRef] [PubMed]

(C) 2016 by the authors; licensee MDPI, Basel, Switzerland. This article is an open access article distributed under the terms and conditions of the Creative Commons by Attribution (CC-BY) license (http:/ / creativecommons.org/licenses/by/4.0/). 